\title{
Indocyanine green fluorescence imaging in robotic surgery: state of art, tips and tricks in current applications
}

\author{
Andre Luiz Gioia MORRELL 1,2,3, Alexander Charles MORRELL1,3, Alexander Charles MORRELL-JUNIOR ${ }^{\mathbf{1}, 2,3}$, \\ Jose Mauricio MENDES ${ }^{1,2,3}$, Francisco TUSTUMI² and Allan Gioia MORRELL1,3
}

\begin{abstract}
Background - Fluorescent imaging with indocyanine green is an emerging technology whose benefits are put in perspective. Objective This article reports essential principles and approaches of intraoperative fluorescence in general surgery bringing familiarity to its practical usage. Our group describes possible pitfalls and provides tips and tricks for training surgeons making their attempts easier and reproducible during practice. Methods - This study overviews the most structured concepts, practical applications and its tricks in robotic fluorescence guided imaging surgery with indocyanine green. Possible pitfalls are emphasized and emerging fields of application are put in a perspective. Results - Guided information and practical applications in several surgical fields are described for a safe and reproducible indocyanine green fluorescence imaging use. Conclusion - Robotic assisted surgery combined to fluorescence imaging technology represents a logical evolution in image guided surgery and technology familiarity with guided information may represent a wider and safer spectrum of use in surgeons' hands.
\end{abstract}

HEADINGS - Robotics. Digestive system surgical procedures. Indocyanine green.

\section{INTRODUCTION}

Indocyanine green (ICG) is a fluorescent molecule whose incident infrared light of wavelength $780 \mathrm{~nm}$ provokes detectable photon emissions to dedicated optical systems ${ }^{(1)}$. Initially used in photography, its medical related applications have been documented since the mid-1950s for hepatic and cardiac function ${ }^{(2)}$. Intravascularly its half-life is about 2.4 minutes by binding to plasma lipoproteins until hepatic uptake and exclusively bile excretion ${ }^{(3)}$.

Very low rates of adverse effects step up its virtually nontoxic using a standard dose of less than $2 \mathrm{mg} / \mathrm{kg}$ in non-iodine allergic patients.

Fluorescence-guided imaging has evolved the last few years however its firsts descriptions date decades ago. Historically, Moore ${ }^{(4)}$ reported the ICG usage in differentiation of normal and malignant tissues applied to neurosurgery. Through implementations of advanced technologies, more complex interventions in the visceral surgery field became feasible with a minimally invasive concept and more recently intraoperative imaging applications are put in a perspective. ICG has found applications in several surgical fields enabling real-time visualization of structures of interests and information assessment that normally are uncertain under naked eyes. Tissue perfusion assessment, anatomic distinction, lymphography and others implementations have been described in general, gynecology, urology, colorectal surgery and surgical oncology practice ${ }^{(5-7)}$.

Even more notorious, robotic-assisted surgery is spreading quickly and has shown to overcome the intrinsic limitations of laparoscopy. High definition, three-dimensional stereoscopic vision and magnification, a stable and surgeon guided camera, improved ergonomics, superior range of motion and motion scaling are remarkable advantages ${ }^{(8)}$. Also available, fluorescence imaging was integrated in 2010 in the Da Vinci Robotic Systems through infrared emission enhancing ICG molecules and providing real-time images of fluorescent structures (Firefly ${ }^{\mathrm{TM}}$ Fluorescence Imaging Scope; Intuitive Surgical, Sunnyvale, CA). Robotic assisted surgery combined to fluorescence imaging technology represents a logical evolution in image guided surgery and its benefits are still in progress.

Intraoperative fluorescence imaging is safe and reproducible among surgeons, however, each application demands a complete understanding of the topic. ICG biochemical properties, fluorescence technology devices, goals of usage, correct timing, location of application as well as patients conditions and possible pitfalls may interfere with your information assessment. The purpose of this article is to summarise the current usage of ICG fluorescence imaging in robotic general surgery and assure information and its correct application with tips and tricks regarding each different area of interest. 


\section{METHODS}

A literature narrative review was conducted regarding characterization of ICG fluorescence imaging applications in the robotic surgery field. Current context and practical experience was also described aiming for better guidance and reaching the goals of usage due to common unknown pitfalls and multiple areas of interest.

\section{Fluorescence imaging technology and ICG}

Fluorescence is caused by incident light that excites the target and causes light emission of a particular wave-length. The ICG molecule is a water-soluble fluorophore that when injected intravenously it quickly becomes protein-bound, confined to the intravascular compartment. When excited between 750 and 800 $\mathrm{nm}$, fluorescence is viewed around the maximum peak of 832 $\mathrm{nm}^{(3)}$. The fluorescent emitted light passes through a sensor in the optical device filtering out other wavelengths, displaying the green light in real-time visualization. Firefly ${ }^{\mathrm{TM}}$ is the da Vinci integrated fluorescence capability that uses near-infrared technology activated at the surgeon console. The dosage and time point of administration, the start of the imaging process and detection of the signal varies depending on the area of interest.

\section{Preparation of ICG for administration}

Under sterile conditions, $25 \mathrm{mg}$ of ICG normally disposed of in one vial is diluted using $10 \mathrm{~mL}$ sterile water for a $2.5 \mathrm{mg} / \mathrm{mL}$ solution vial. This solution for injection must be used within 6 hours after reconstitution otherwise precipitation may be present requiring discard of the solution. For intravenous purposes, administration followed by an immediate intravenous flush of $10 \mathrm{~mL}$ of an isotonic solution is encouraged to allow the dye to reach the intravascular compartment quickly and not be retained in the venous access. ICG administration may be performed via a central or peripheral venous line and multiple doses can be administered as required, up to the maximum recommended total dose of dye, kept below $2 \mathrm{mg} / \mathrm{kg}$. In situ tissue administration is also applied for fluorescence lyphograpy or anatomic enhancement and its doses and methods are discussed separately.

\section{APPLICATIONS}

\section{Tissue perfusion assessment}

Based on the ability of ICG to become fluorescent, real-time intraoperative organ perfusion evaluation has been used in several clinical applications. The optimal time to detect a fluorescence signal varies between 25-60 seconds after administration and the signal peak is around 30-40 seconds after administration, losing intensity within 2 minutes. Literature reports variable dosages of ICG usage depending on patients bodyweight, ranging most of the studies from $2.5-10 \mathrm{mg}$. A $7.5 \mathrm{mg}$ dose followed by a $10 \mathrm{~mL}$ bolus of saline in a coordinated administration should be performed by the anesthesiologist whenever asked by the surgeon and the area of interest must be already exposed and targeted by the surgeon's endoscope. On the console display, the surgeon activates the Firefly $^{\mathrm{TM}}$ mode for enabling infrared emission to promote excitation and fluorescence of the desired tissue (FIGURE 1). Intensity peak and washout may be affected by the patient's circulatory condition as well as cardio-circulatory inotropes. A weak signal might be present if a long distance between the camera and the tissue is present. Also, a slow injection of the dye or a lack of flushing afterwards may contribute to fluorescence misinterpretation.

FIGURE 1. A. Image spectrum as usual in robotic optics. B. Fluorescence through indocyanine green Firefly ${ }^{\mathrm{TM}}$ technology activated. C. Indocyanine green bottles to create the greenish solution. D. Activation of Firefly mode with surgeon's console command.

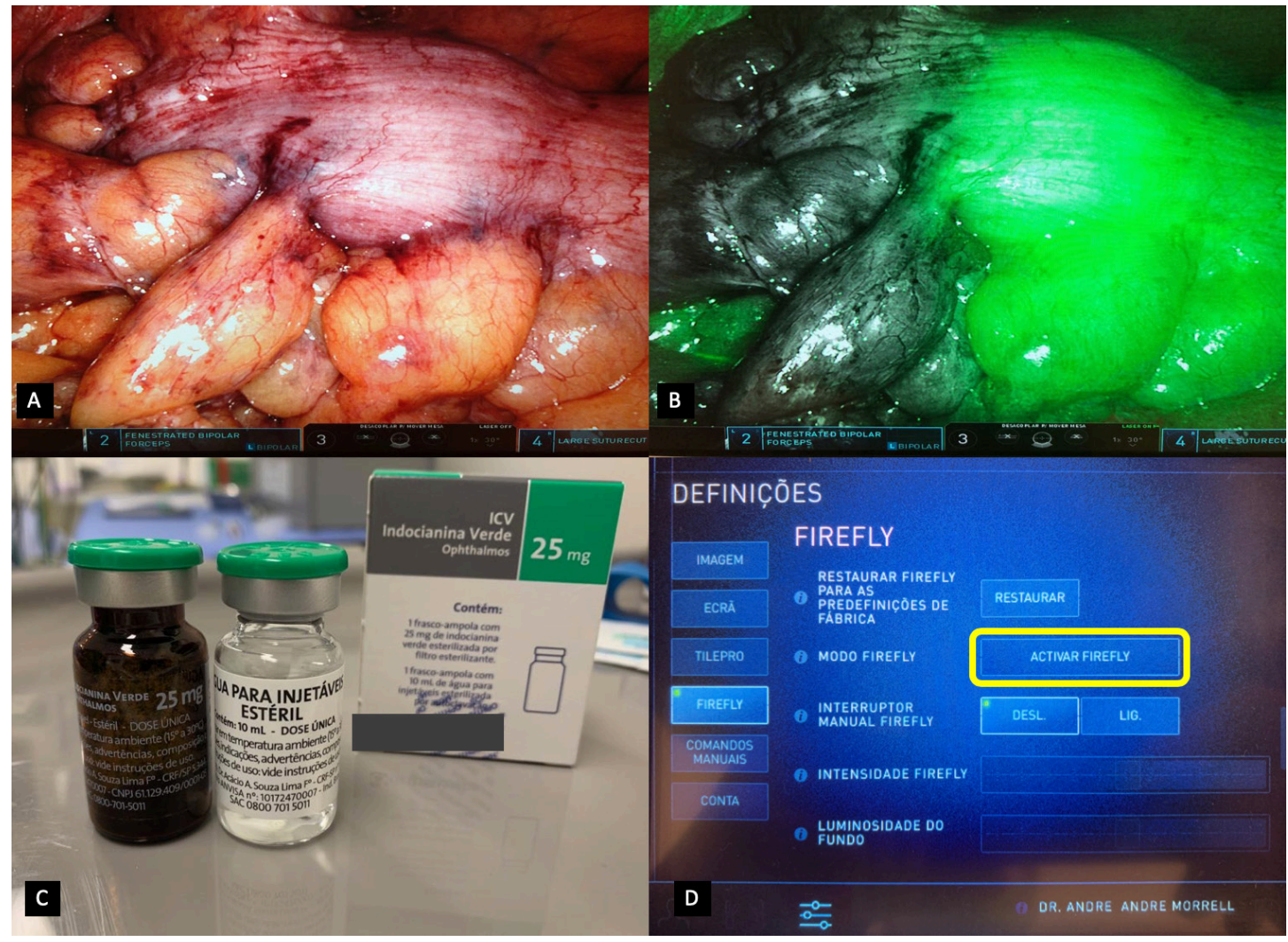




\section{Upper GI tract surgery}

ICG tissue angiography might guide the identification of the optimal resection site and help estimate the blood supply of upper GI tissue and visceral anastomosis. Regarding esophageal surgery field, fluorescence imaging has been documented to early assess the graft perfusion and its vascularity web. Esophageal reconstruction is typically done with a tubularized gastric graft perfused by the right gastroepiploic arcade and the perfusion in proximal portion of the it, area where the anastomosis is typically created, is variable and often tenuous because the arcade rarely reaches its top. ICG image guided technology intraoperatively encourages correlation between adequate perfusion assessment and reduction anastomotic leak rates in these procedures ${ }^{(9,10)}$. Zehetner et al. ${ }^{(11)}$ also described lower leakage rates in patients following esophagectomies when the anastomosis was placed in an area of good perfusion after fluorescence image. Intraoperative assessment of the conduit perfusion should be done by peripheral or central-line injection of $7.5 \mathrm{mg} \mathrm{ICG}$ immediately followed by a $10 \mathrm{~mL}$ flushing with saline, expecting its peak within 30 seconds. Kumagai et al. ${ }^{(12)}$ recently reported a 90 -second rule advocating a safer method to assure adequate tissue perfusion. Anastomosis blood supply may also be performed robotically whenever opting for an intrathoracic technique.

Bariatric surgery also represents a novel branch for this technology, especially to estimate the risk of leak after sleeve gastrectomies, gastric bypass anastomosis and revisional procedures (FIGURE 2.A, B). Di furia et al. ${ }^{(13)}$ described a 43 patients analysis of minimally invasive sleeve gastrectomies with ICG perfusion assessment however without a well established correlation between gastric leak and sleeve conduit blood supply. Larger series and prospective trials still are needed in order to provide higher levels of evidence sup- porting ICG usage for tissue assessment in standard procedures. As for revisional bariatric surgeries, due to heterogeneity of cases, controlled studies still lack in literature.

\section{Colorectal surgery}

ICG perfusion assessment has found a broad field in colorectal surgery, used mainly to assess the perfusion of performed anastomosis and sites before deciding where to resect the bowel (FIGURE 2.C, D). The prospective multicenter study PILLAR II trial, reported lower anastomosis leakage rates compared to literature, $1.4 \%$ to $3-15 \%$ respectively in patients undergoing left sided colectomies and low anterior resections ${ }^{(14)}$. Also, systematic review data step up for the same results, stating half of leakage rates in patients utilizing ICG fluorescence image technology compared to its absence ${ }^{(15)}$. The latest meta-analysis regarding colon and rectal cancer surgeries recruited more than 1300 patients with significant reduction of anastomotic leak associated with ICG angiography. Not only important for checking anastomosis integrity, the real-time fluorescence guided image has also demonstrated changes in the operative technique and bowel transection area ${ }^{(16)}$.

For an efficient angiography during colorectal surgery, the ICG usage should be divided in two different steps: first, the planned point of proximal and distal transection area just before bowel resection, to assure a correct transection line and well perfused remnant bowel (FIGURE 3.A, B). Second, after completion of the anastomosis, another course of ICG injection is encouraged to visualize the integrity of anastomosis and its vascularity (FIGURE 3.C, D). If a low colorectal anastomosis is performed, a third optional step by visualization of the rectum and anastomosis mucosa may be achieved with an additional Firefly ${ }^{\mathrm{TM}}$ integrated endoscope via proctoscopy.

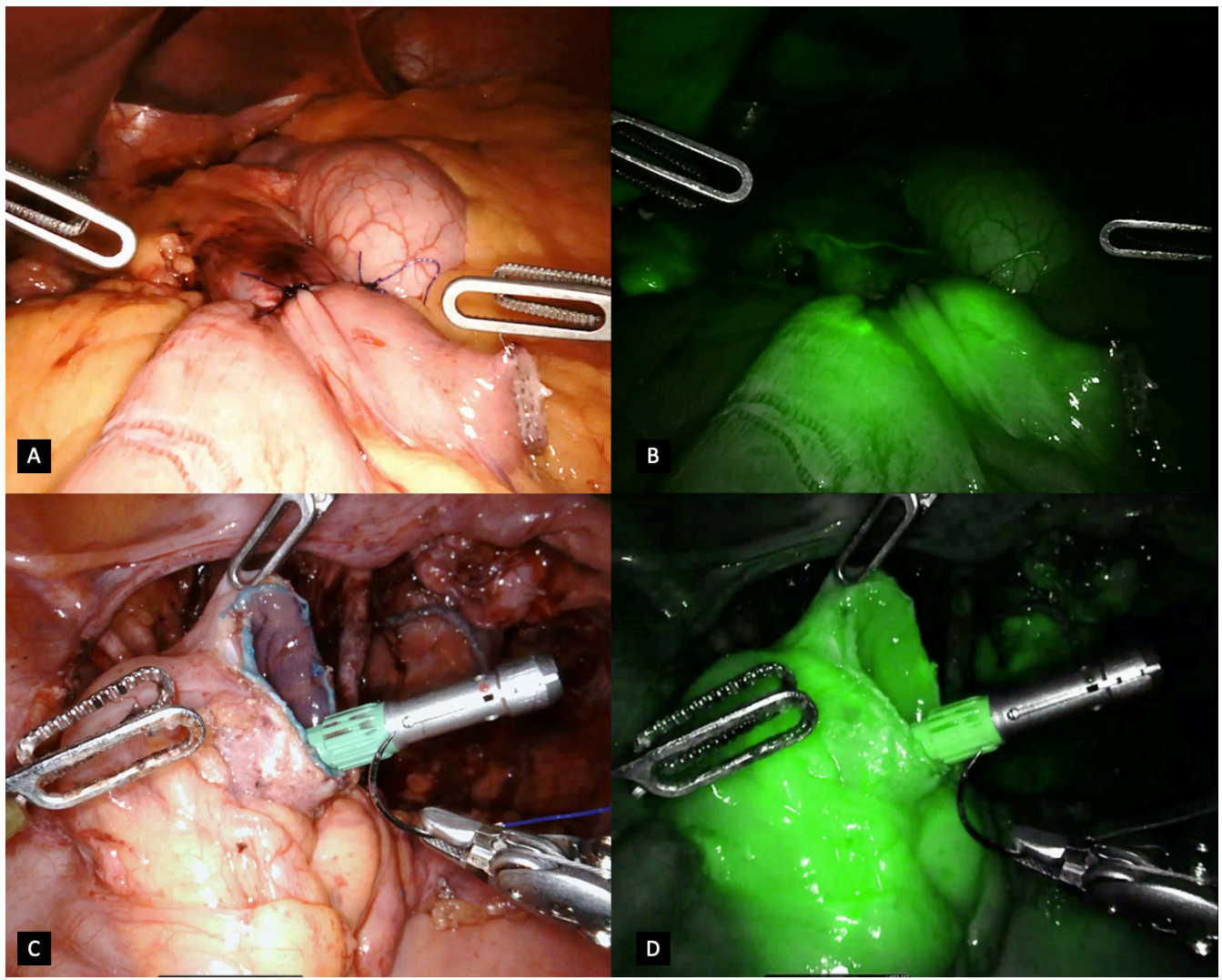

FIGURE 2. A. Spectrum of images in the usual form of gastrointestinal anastomosis. B. Gastrointestinal anastomosis seen with indocyanine green image guided fluorescence, with adequate tissue perfusion. C. Spectrum of images in the usual form of colonic segment before a colorectal anastomosis. D. Colon segment visualized with direct guided fluorescence imaging showing good blood supply. 
FIGURE 3. A. Bowel segment after mesenteric ligation in the usual color spectrum of the robotic endoscope. B. Bowel segment in real time detailed visualization of the well-perfused and ischemic segment. C. Colorectal anastomosis with usual visualization. D. Colorectal anastomosis with the Firefly ${ }^{\mathrm{TM}}$ mode activated, emitting direct fluorescence and showing good perfusion.

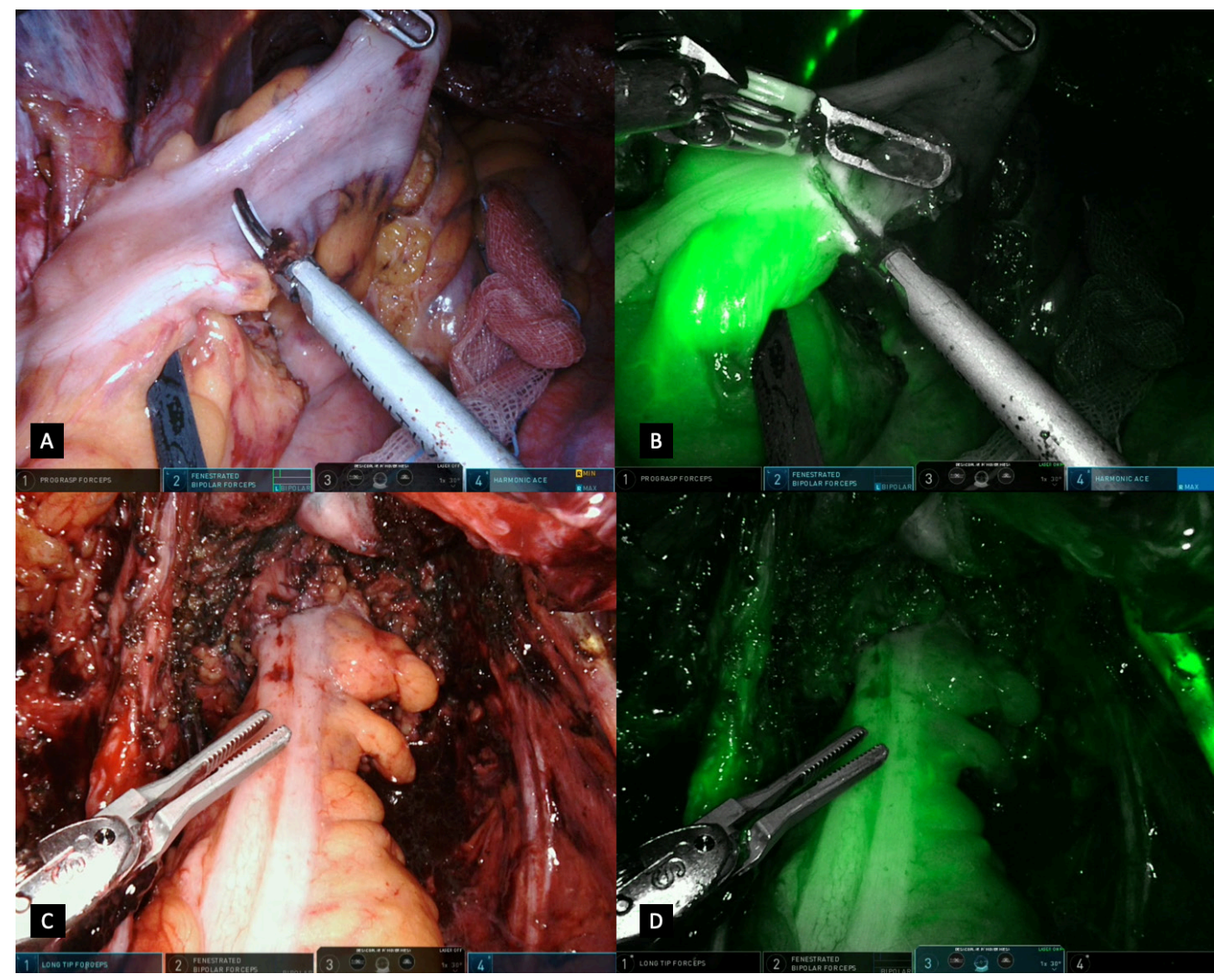

Also, literature reports most of colectomies from oncological procedures however the tissue perfusion assessment is expanded to all others colorectal conditions, such as diverticulitis and diverticular disease, crohn and ulcerative colitis resections, deep infiltrating endometriosis and bowel affections.

\section{Hepatobiliary surgery}

Regarding tissue perfusion assessment, in liver surgery, ICG is still mainly used as a reagent for the evaluation of hepatic function. ICG elimination depends on hepatic blood flow, hepatocellular function and biliary excretion a due to pharmaco characteristics, its elimination considered as a useful dynamic test describing liver function and perfusion in the perioperative setting, in liver surgery and transplantation, as well as in critically ill patients. Also, ICG accumulates in the cancerous tissues of hepatocellular carcinoma (HCC) and in the noncancerous hepatic parenchyma around adenocarcinoma foci, which may be used to increase detection. Tumor boundaries and residual lesions are also achieved through real-time fluorescence.

Whenever using the ICG fluorescence for hepatic surgeries, some important aspects must be addressed. Liver fluorescence may be achieved from intravenous peripheral or central access administration or by a local intraoperative puncture injection such as portal vein or right gastric vessels. If ICG administration is done by peripheral or central venous access, liver fluorescence is expected in 5minutes; different from local intra abdominal injection whose liver enhancement develops rapidly within $1-2 \mathrm{~min}$. A $0.25 \mathrm{mg} / \mathrm{kg}$ concentration of ICG should be injected and after administration 


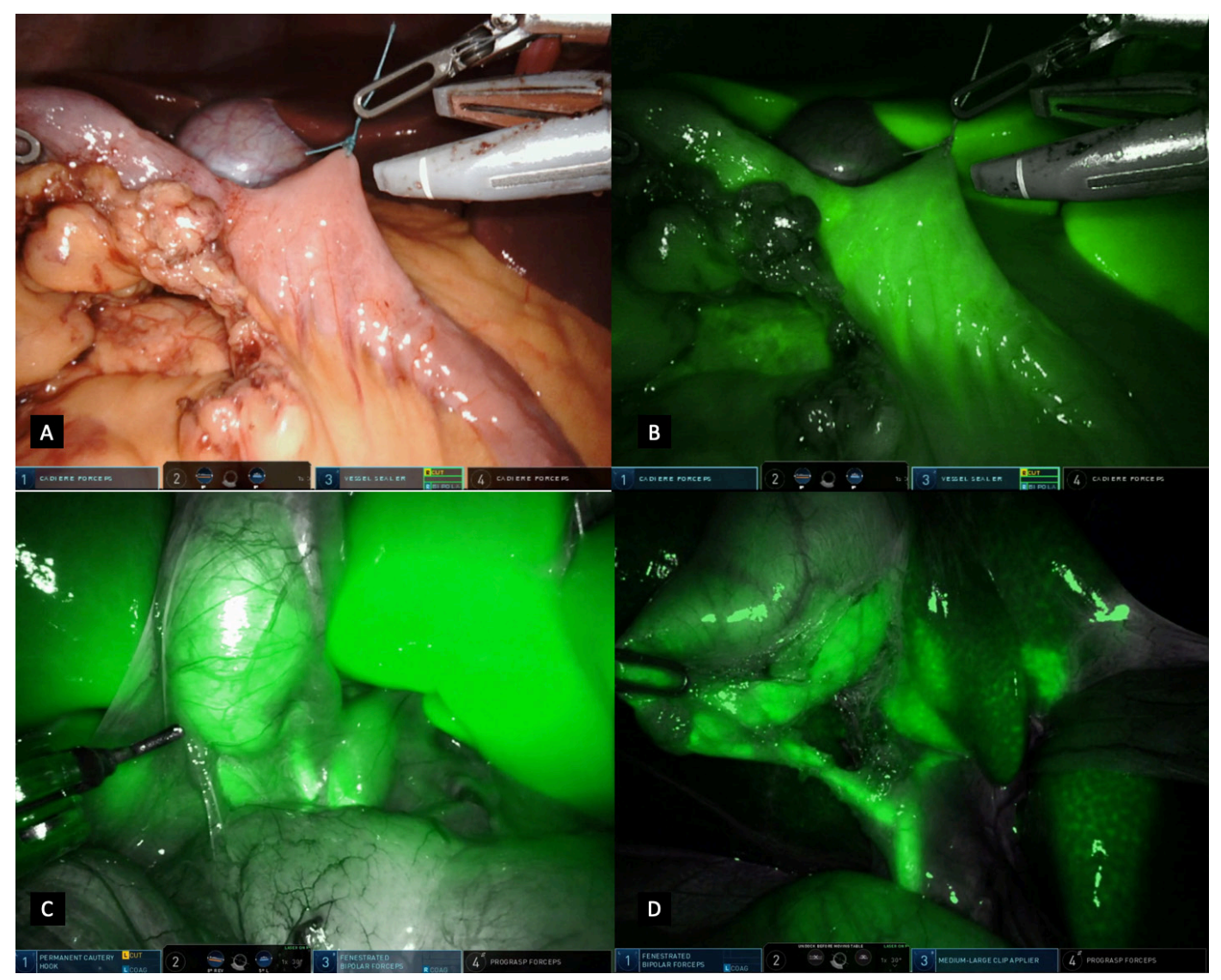

FIGURE 4. A. bowel segment before section under normal visualization. B. Bowel segment under direct visualization with fluorescence and tissue perfusion assessment. C. Biliary tree visualized with fluorescence mode made with indocyanine green injected intraoperatively. D. Biliary tree highlighted under fluorescence image with indocyanine green injected 4 hours prior to surgical procedure.

of the drug, tumors will appear as a shadow with a Firefly ${ }^{\mathrm{TM}}$ mode, as compared with normal liver tissues. Cirrhotic tissues are used to develop slowly and not uniform patterns of enhancement, a pitfall if not previously known.

A second manner of enhancing the visualization of lesions is by injecting the ICG the day before surgery, which will provide clearance of the substance in the normal hepatic parenchyma with residual stain in the altered tissue area. Also, for a better hepatic transection line visualization and perfusion enhancement in major hepatectomies, after clamping or ligation the portal pedicle and arterial branch, ICG administration also will enlighten the remnant liver tissue in contrast to the non well perfused.

Regarding pancreatic surgery, ICG fluorescence can be useful to identify pancreas tumors in patients undergoing pancreas resection, specifically neuroendocrine tumors and cystic neoplasms. A low dose of $2.5 \mathrm{mg}$ can be injected intraoperatively; having neuroendocrine tumors enhanced with a higher fluorescence signal compared to pancreatic tissue; opposed to cystic neoplasms, which will display lesser fluorescence intensity compared to normal tissue.

\section{Urgent surgery}

ICG fluorescence angiography could be an objective and noninvasive method to assess intestinal viability to determine the extent of ischemia correctly. This application may be useful in bowel related cases, such as incarcerated or strangulated hernias, mesocolic or mesenteric dissection in adherences and obstructive diseases or even acute mesenteric ischemia. Similar to bowel perfusion assessment described previously, ICG administration by central ou peripheral catheter may help decision-making in challenging cases whenever naked eyes cannot assure optimal analysis.

\section{ANATOMIC IDENTIFICATION}

Safety during surgery has always been a matter of concern during advanced minimally invasive procedures. Identifying the correct anatomical plane and surrounding structures can be extremely demanding, requiring extensive knowledge and foresight. However, even in experienced hands, some challenging situations whereas anatomical variations, acute inflammation or adhesions may contribute to misunderstanding of the usual landmarks. Thus, fluorescence imaging enhances and helps visualization of some anatomic structures, aiming for better identification and prevention of inadvertent injuries.

\section{Biliary anatomy}

ICG fluorescence imaging to visualize and elucidate biliary anatomy represents one of the most established applications of this technology in abdominal surgery. Due to ICG excretion into bile entirely by the liver, its mechanism of enhancement became obvious. A special attention should be addressed to the time of injection when opting for the optimal biliary tree anatomy contrast during surgery. Different from what happens when aiming tissue perfusion assessment, the ICG administration should be performed at least 4 hours prior to surgery. Whenever possible, ICG injection may be achieved even $24 \mathrm{~h}$ before the procedure. A premature administration of the dye will allow hepatic parenquima metabolize the 
pigment and secrete into bile; avoiding green stains in liver tissue only accumulation of ICG inside the bile ducts (FIGURE 4.C, D). Injecting the ICG during intraoperative dissection for better biliary tree identification is one of the most important pitfalls in image guided fluorescence technology.

A 0.25 to $0.35 \mathrm{mg} / \mathrm{kg}$ dose of ICG should be administered minimum 4 hours prior to surgery, not exceeding $2 \mathrm{mg} / \mathrm{kg}$ maximum dosage, in peripheral or central venous access for the optimal bile ducts visualization. Once instruments and scope are ready, no additional injection of ICG is normally required during the procedure. Using the Firefly ${ }^{\mathrm{TM}}$ technology, the triangle of calot is easier exposed for common bile visualization as well as cystic duct whenever doing a cholecystectomy. The structures containing residual bile would be highlighted by the green stain and others structures such vascular or parenquima tissue will remain dark. If an acute cholecystitis with obliteration of the cystic duct caused by a stone is seen, the ICG fluorescence may not make the whole cystic duct and the gallbladder stained, due to inability of the dye to achieve that space. In this scenario, injection of ICG directly into the gallbladder may help elucidating the anatomy from a reverse perspective. Special care should be taken not to leak out the ICG in the surgical field, otherwise the dye will blush the non-biliary structures making impossible the optimal visualization.

\section{Ureter identification}

Intraoperative identification of the ureters can be challenging in some pelvic surgeries due to neoplastic diseases, previous surgery with distortion of natural surgical planes, inflammatory bowel conditions, deep infiltrating endometriosis or adhesions.
For accurate and easier localization of ureters during minimally invasive surgery, fluorescence of ureters can be achieved through some methods.

In one possibility, a real time cystoscopy-guided, ureteral cannulation is done with 6-Fr ureteral catheter and a retrograde instillation of $5 \mathrm{mg}$ ICG dye is performed preoperatively followed by $10 \mathrm{~mL}$ saline flush. Greenish fluorescence guided image in the ureters will occur due to ICG binding to the proteins of the ureteric epithelium (FIGURE 5.A, B). During the procedure, turning the Firefly ${ }^{\mathrm{TM}}$ mode active by the surgeon at the console will make the structure enlightened compared to the darkened tissues aside. No intraoperative or intravenous administration of ICG is necessary for this purpose. Another possibility to assure ureter identification intraoperatively is by placing lighted ureteral stents (FIGURE 5.C, D). Also through a preoperative cystoscopyguided cannulation, both ureters may have the illuminated catheter positioned to a better identification and overcome some limitations of tactile feedback.

\section{Leak tests}

Leak tests using air or methylene blue are often performed to assess anastomosis or suture integrity in upper GI (gastrointestinal) procedures, such as bariatric gastric bypass, sleeve or oncological gastrectomies, or even urgent cases such as gastric or duodenal suture due to ulcer perforation. Similar to the methylene blue dye, however easily visible even in small amounts and fluorescent with laser excitement, the ICG has shown to be an excellent agent for leak testing through fluorescence image guided technology.

Both upper GI tract and colorectal procedures may use ICG to
FIGURE 5. A. Ureter visualized after dissection in pelvic surgery. $\mathrm{B}$. Bilateral ureteral enhancement through fluorescence with indocyanine green. C. Left ureter covered by the peritoneal flap under usual visualization. D. Left ureteral enhancement in real time with Firefly mode activation during colorectal surgery.
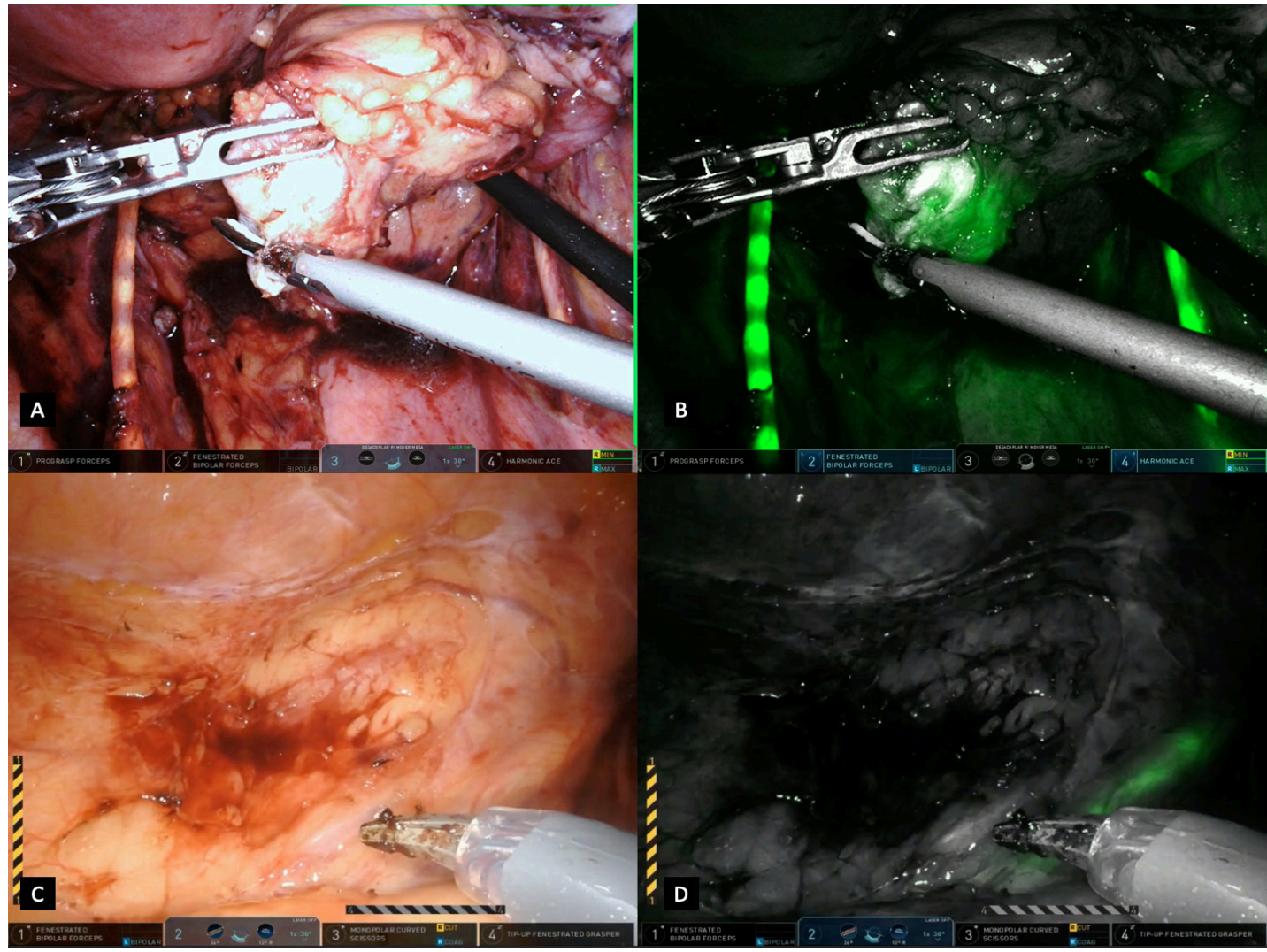
test anastomosis or suture integrity. By diluting the $25 \mathrm{mg}$ of ICG to $250 \mathrm{~mL}$ of sterile water, this green stained solution is administered through a nasogastric tube or rectal catheter. Whenever performing the leak test in the upper GI tract, the nasogastric tube should be placed according to the desired landmark and distal bowel or gastric tissue need to be bluntly occluded to assure anastomosis pressure (FIGURE 6.A). After correct occlusion of the distal part, the surgeon in the console orders the anesthesiologist to administer the ICG and Firefly ${ }^{\mathrm{TM}}$ mode should be activated. Greenish leak is evident whenever present. In colorectal anastomosis, the patient should be placed in a trendelenburg position and the proximal bowel occluded bluntly by the surgeon, asking the bedside assistant to inject retrograde through the rectal stent the ICG dye, followed by activation of the Firefly ${ }^{\mathrm{TM}}$ technology.

Assessment of bile leak test is also a possibility of ICG fluorescence imaging in robotic hepatic surgery (FIGURE 6.B, $\mathrm{C}, \mathrm{D})$. By inserting a $5 \mathrm{Fr}$ or $6 \mathrm{Fr}$ soft tube into the common bile duct through the stump of the cystic, a solution of $25 \mathrm{mg}$ of ICG diluted to $100 \mathrm{~mL}$ of sterile water is injected before liver parenchymal transection. Distal common bile duct should be clamped to avoid outflow of the dye to the duodenum and provide a higher pressure in the biliary tree. Activating the Firefly ${ }^{\mathrm{TM}}$ filter, bile leaks from the transected liver surface are able to be identified under real-time visualization with greenish enhancement of the parenquimal area. Chyle leak test through ICG administration can be also performed to obtain real-time fluorescent images of lymph flow. An ICG lymphography is achieved by subcutaneous injection of ICG into nearby lymph node regions, then the chyle flow image will be visualized in a greenish fluid intraoperatively when active in the Firefly ${ }^{\mathrm{TM}}$ technology.

\section{Endometriosis}

The diagnosis of peritoneal endometriosis during minimally invasive procedures may be difficult due to the polymorphic aspects of the lesions. The need for better visualization led to a rise in literature the use of contrast agents, such as ICG fluorescence imaging. Only few studies have reported evident improvement in detecting the endometrial tissue, although the ICG applications for a safe deep infiltrating endometriosis surgery and bowel resection is widely known ${ }^{(6)}$. Limited data is available to support the ICG fluorescence guided image to assure correct visualization of endometriosis in the peritoneal cavity.

\section{Vascular anatomy}

Vascular structures identification is one of the most important steps in every surgical procedure. By injecting the ICG solution intravenously, a real-time green fluorescence image is shown in blood vessels followed by tissue perfusion. Several abdominal surgeries may be helped in difficult decision-making dissections due to vascularity assessment. In colorectal procedures, identifying the inferior mesenteric artery (IMA) or left colic vessels during robotic rectal resection can be easily performed through ICG fluorescence technology. In upper GI tract surgeries, fluorescence can assure better identification of vascular anatomy of the infrapyloric artery in pylorus-preserving gastrectomies, or anatomy highlight of the hepatic and gastroduodenal arteries for a safe lymphadenectomy. In urologic field, selective arterial clamping with ICG fluorescence image provides an intraoperative renal angiogram so that he can selectively clamp minor arteries instead of clamping the main renal artery. Additionally, robotic assisted prostatectomies can be supplemented by ICG imaging to identify the prostatic neurovas-

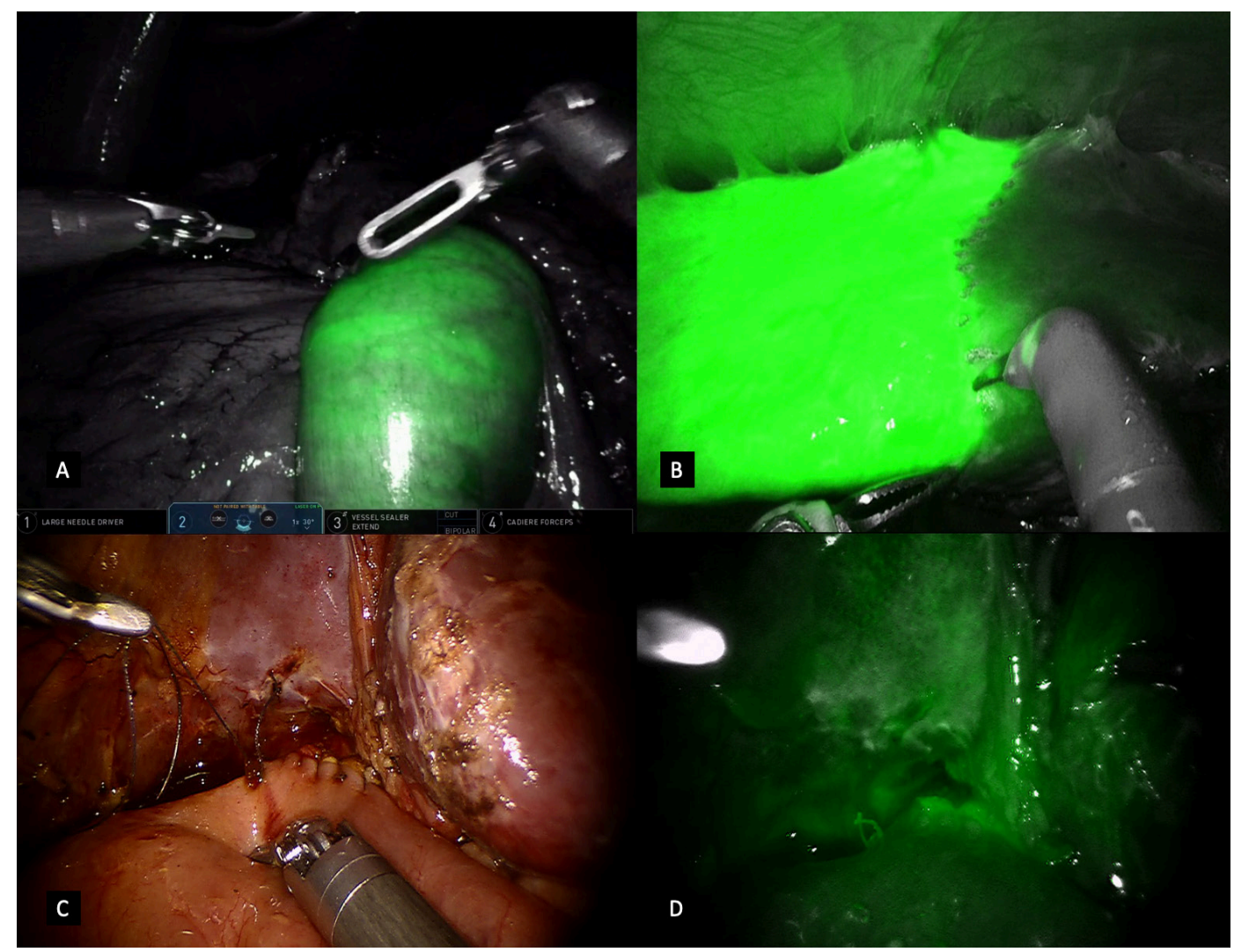

FIGURE 6. A. Leak test in gastrojejunal anastomosis with infusion of indocyanine green via endoluminal catheter. B. Enhancement of the well-perfused liver parenchyma in contrast to non-vascularized tissue. C. Biliodigestive anastomosis under habitual view. D. Bile leak test in hepatojejunostomy under fluorescence guided image. 
cular bundles. Angiography for vascular identification is similarly performed as previously described for tissue perfusion assessment, with $7.5 \mathrm{mg}$ of ICG followed by a $10 \mathrm{~mL}$ saline flush coordinated between surgeon and anesthesiologist.

\section{FLUORESCENCE LYMPHOGRAPHY AND LYMPH NODE NAVIGATION}

ICG has the property of lymphatic tropism and after submucosal or subserosal injection, it can follow the lymphatic vessels and accumulate in the lymph nodes. For an accurate lymphatic mapping, the dye should be administered submucosally and draining lymph nodes will be visualized intraoperatively. Whenever performing oncological procedures, guided lymphatic mapping may assure a more precise resection, staging or lymphadenectomy. A $2.5 \mathrm{mg} /$ $\mathrm{mL}$ solution of ICG should be prepared as previously described and administered according to the area of interest. In colorectal diseases, greenish enhancement through fluorescence is achieved by a colonoscopy-guided submucosal injection of $2.5 \mathrm{mg}$ of ICG solution in each four cardinal sites around the tumour the day before surgery, representing $4 \mathrm{~mL}$ in total. For a real-time visualization, the surgeon must turn on the Firefly ${ }^{\mathrm{TM}}$ mode for excitement of ICG molecules and standard fluorescence. Intraoperative ICG administration through subserosal injection around the lesion is also possible, however if any spill occurs the surgical field becomes blushed and fluorescence image is compromised. In rectal cancer, the lymphography may be helpful especially to detect the lymphatic drainage across the lateral lymph nodes and guide its removal. Also, in colon cancer whenever opting for a complete mesocolic excision technique, the fluorescence assessment could be useful for a safe and optimal D3 lymphadenectomy.

In the upper GI tract, an endoscopy-guided injection is also performed in 4 sites of the submucosa tissue around the gastric or esophageal lesion the day before surgery. Fluorescence guided image can be visualized as previously described and the use of ICG may offer some advantages in lymph node visualization over other modalities of dyes or radioisotopes. Under real-time lymphography, lymph node stations are accessed having a better visualization regarding disease staging as well as safety and completeness of the lymphadenectomy.

\section{DISCUSSION}

Indocyanine-green fluorescence imaging is an emerging technology and has several applications in the surgical field for information assessment and intraoperative decision-making. Current clinical practice has a broad spectrum of use and its real benefits are put in perspective more recently. In general surgery, different manners of use are reported as tissue perfusion assessment, anatomic identification and lymphography from upper GI tract to colorectal procedures ${ }^{(5,6,9,10)}$. Information like the correct dosage and dilution, the way of application whether fractionated or in bolus, and the exact time of use due to its degradation and kinetics are not evident in most of the available studies. A guided description of practical usage with well defined concepts and tricks could overcome limitations of unfamiliarity to the technology due to heterogeneity of methods reported.

The imaging of fluorescence emitted by ICG is a fast, simple, and relatively inexpensive tool without side effects. The ICG tissue angiography concept described in this report provides the surgeon a clear guide and advice on how to exactly perform an intraoperative ICG fluorescence angiography. Bringing familiarity to the dosage and practical measures, as well as pointing out possible pitfalls could help its use in training surgeons. Several studies have proven the efficacy of ICG fluorescence imaging in assessing bowel perfu$\operatorname{sion}^{(17,18)}$. Uncoordinated administration or image capturing long after/or even before injecting the dye might lead to acquisition of false data causing misinterpretation of the tissue perfusion. To assess intestinal perfusion most studies suggest 2.5-10 mg of ICG depending on the body weight. A change in the transection line was performed in up to $40 \%$ of patients undergoing colorectal resections described by Hellan et al. ${ }^{(19)}$. Also, a case-control study has already reported lower rates of anastomotic leak compared to non-ICG related procedures ${ }^{(14)}$

Regarding upper GI tract, ICG has also been extended to a wide surgical field, with more concrete results in esophageal reconstruction procedures. A meta-analysis by Ladak et al. ${ }^{(9)}$ recently evidenced a $69 \%$ reduction in anastomotic leaks in esophageal procedures with ICG fluorescence combined to intraoperative interventions. Due to encouraging results, fluorescence has been also extended for bariatric surgeries aiming for better outcomes. Its worldwide know that gastric bypass and sleeve gastrectomies are not free from adverse events; having the most worrying complications anastomosis and gastric leaks. Few studies in literature describes ICG use in perfusion assessment during bariatric procedures and preliminary results with clinical benefits still inconclusive ${ }^{(13,20)}$.

In the hepatobiliary field, a unanimous consensus in the literature pertains to anatomic real-time visualization of the biliary tree. Comparative studies and systematic reviews are robust when describing its benefits in what is perhaps the most established ICG fluorescence guided image in recognition of anatomy used by general surgeons ${ }^{(21,22,23)}$. As previously mentioned, the optimal common bile duct fluorescence identification in cholecystectomies depends on the dosage and administration interval of ICG. It is reported to have better visualization if injected hours before the surgery than at the time of the procedure, with different patterns of contrast of the bile duct in relation to background normal liver tissue ${ }^{(24)}$.

Although not an intraoperative fluorescence technology, another interesting ICG application is regarding perioperative efforts. Decades ago Hemming et al. ${ }^{(25)}$ reported in cirrhotic patients that preoperative ICG elimination kinetics were independent predictors of postoperative mortality. The ICG plasma disappearance rate could be used to help decision making prior to major liver resections in order to minimize the risk of postoperative liver failure. More specific to surgical oncology hepatobiliary context, a recent meta-analysis showed that additional ICG fluorescence does decrease operative time, blood loss, hospital stay, and postoperative complications ${ }^{(26)}$. Also, some oncological cases may have benefits from ICG properties since its discovery of accumulation in the cancerous tissues of neoplastic lesions, such as hepatocellular carcinoma and in the noncancerous hepatic parenchyma around adenocarcinoma foci by Ishizawa et al. ${ }^{(27)}$. In clinical practice, improvement in detection of lesions is reported however further substantial data regarding sensibility and outcomes is still required.

In the surgical oncology field, the potential benefit associating ICG fluorescence imaging in gastrointestinal lymphography is another important topic explored in literature. Although studies demonstrate ICG as being superior to some radioactive tracers 
and dyes in node navigation, its real clinical benefits are still in perspective. Herrera-Almario et al. ${ }^{(28)}$ reported its application in oncological gastric resections providing real time intraoperative feedback regarding lymph node identification with a surgical time increase of less than $10 \mathrm{~min}$. More recently, Cianchi et al. ${ }^{(29)}$ in a matched cohort study described additional node detection during robotic surgery for gastric cancer. Despite a higher number of total lymph nodes harvested in the ICG group, its results failed to show good selectivity for metastatic occurence. In the hepatopancreatobiliary scenario, Machado et al. ${ }^{(30)}$ even described an intraoperative localization of the ampulla of Vater performed with Firefly ${ }^{\mathrm{TM}}$ fluorescence defining the superior margin of the resection in a robotic resection of the uncinate process of the pancreas. In colorectal oncology, lymphography has also been reported both in colon and rectal cancer ${ }^{(31)}$. In selective colonic cases, ICG fluorescence adoption in complete mesocolic excisions could allow a more reliable lymphadenectomy. Also, in rectal cancer surgery, extending lymphadenectomy to lateral pelvic nodes could help in reduction rates of nodal recurrence ${ }^{(32)}$.

Although recent, the robotic ICG intraoperative fluorescence imaging with ICG has spread into numerous interesting applications in general surgery. Several other surgical fields are still in perspective such as fluorescent tumor-binding agents, peritoneal carcinomatosis diagnosis and even indocyanine green nanoparticles $^{(33,34)}$. An important issue pertains to the costs, reproducibility and safety of this technology. The major positive feature is that training required is minimal and the learning curve is short, having a real-time visualization activated by a simple button click in the console. Costs also stand as minimal values once the robotic platform has Firefly ${ }^{\mathrm{TM}}$ technology already integrated and ICG solutions present affordable prices. In summary ICG fluorescence combined with robotic surgery has shown to be an important game changer in the surgeons armamentarium.

This report presents an overview of current ICG fluorescence imaging technological concepts and tips and tricks of its applications in robotic-assisted general surgery. Guided information and well known steps could help bring familiarity to training surgeons and make their attempts easier and more reproducible during practice. Although numerous interesting applications and encour- aging outcomes, it remains to be proven whether ICG increments procedure-specific advances or real clinically substantial benefits in some yet unclear surgical fields.

\section{CONCLUSION}

Fluorescence-guided surgery is one of the most innovative examples of surgery integrated to images; which may hopefully provide better healthcare. The robotic platform integrated to ICG intraoperative fluorescence imaging has found numerous interesting applications in visceral surgery more recently, raising the hope that future studies will allow us to perform more precise surgery with less perioperative complications. Guided steps could assure an even wider spectrum of this resource use and safety in training surgeons, whose applications are vast and evidence is emerging showing another weapon in the robotic surgeon's armamentarium yielding tangible clinical benefits.

\section{ACKNOWLEDGMENTS}

The authors thank all of staff members and the multidisciplinary health team for collaboration during this study's development. The research and education institutes are especially recognized for all their support.

\section{Authors' contribution}

Morrell ALG: conceived of the presented idea. Morrell AC: developed the theory and performed the computations. Mendes JM and Morrell-Junior AC: verified the analytical methods. Tustumi F and Morrell AG: supervised the findings of this work. All authors discussed the results and contributed to the final manuscript.

\section{Orcid}

André Luiz Gioia Morrell: 0000-0003-3971-349X.

Alexander Charles Morrell: 0000-0002-4603-6004.

Alexander Charles Morrell-Junior: 0000-0001-9337-2759.

Jose Mauricio Mendes: 0000-0003-0957-5751.

Francisco Tustumi: 0000-0001-6695-0496.

Allan Gioia Morrell: 0000-0002-5406-0426.

Morrell ALG, Morrell AC, Morrell-Junior AC, Mendes JM, Tustumi F, Morrell AG. Cirurgia robótica guiada por fluorescência com indocianina verde: aplicações, dicas e truques. Arq Gastroenterol. 2021;58(1):61-70.

RESUMO - Contexto - A imagem fluorescente com verde de indocianina (VI) é uma técnica cirúrgica emergente na cirurgia robótica. Objetivo - Este artigo relata princípios e abordagens essenciais da fluorescência intraoperatória para sua prática em cirurgia geral. Nosso grupo descreve possíveis armadilhas e apresenta dicas e truques para treinar cirurgiões, tornando o uso do VI reprodutível. Métodos - Este estudo apresenta uma visão geral dos conceitos e aplicações práticas da imagem guiada por fluorescência com VI na cirurgia robótica. As possíveis armadilhas são enfatizadas e os campos de aplicação emergentes são colocados em perspectiva. Resultados - Aplicações práticas em vários campos cirúrgicos são descritas para um uso seguro e reprodutível de imagens de fluorescência com VI. Conclusão - A cirurgia assistida por robótica combinada à tecnologia de imagem de fluorescência representa uma evolução lógica na cirurgia guiada por imagem e a familiaridade desta técnica pode representar um ganho da qualidade cirúrgica.

DESCRITORES - Robótica. Procedimentos Cirúrgicos do sistema digestório. Verde de indocianina. 


\section{REFERENCES}

1. Landsman ML, Kwant G, Mook GA, Zijlstra WG. Light-absorbing properties, stability, and spectral stabilization of indocyanine green. J Appl Physiol. 1976;40:575-83

2. Yannuzzi L. Indocyanine green angiography: a perspective on use in the clinica setting. Am J Ophthalmol. 2011;151:745-51

3. Alander JT, Kaartinen I, Laakso A, Pätilä T, Spillmann T, Tuchin VV. A review of indocyanine green fluorescent imaging in surgery. Int J Biomed Imaging. 2012;2012:940585.

4. Moore GE. Fluorescein as an Agent in the Differentiation of Normal and Malignant Tissues. Science. 1947;106:130-1.

5. Boni L, Fingerhut A, Marzorati A, Rausei S, Dionigi G, Cassinotti E. Indocyanine green fluorescence angiography during laparoscopic low anterior resection: results of a case- matched study. Surg Endosc. 2017;31:1836-40.

6. Morrell ALG, Ribeiro GMPAR, Santos TP, Chamie LP, Frare N, Serafini PC, Ribeiro DMFR. Robotic Natural Orifice Specimen Extraction with Totally Intracorporeal Anastomosis Associated with Firefly Fluorescence: Bowel Resection for Deep Infiltrating Endometriosis. Journal of Gynecologic Surgery. 2020 128-35.

7. Bates AS, Patel VR. Applications of indocyanine green in robotic urology. J Robot Surg. 2016;10:357-9.

8. Damle A, Damle RN, Flahive JM, Schlussel AT, Davids JS, Sturrock PR, et al Diffusion of technology: Trends in robotic-assisted colorectal surgery. Am J Surg. 2017;214:820.

9. Ladak F, Dang JT, Switzer N, Mocanu V, Tian C, Birch D, et al. Indocyanine green for the prevention of anastomotic leaks following esophagectomy: a meta-analysis. Surg Endosc. 2019;33:384-94.

10. Karampinis I, Ronellenfitsch U, Mertens C, Gerken A, Hetjens S, Post S, et al. Indocyanine green tissue angiography affects anastomotic leakage after esophagectomy. A retrospective, case-control study. Int J Surg. 2017;48 $210-4$.

11. Zehetner J, DeMeester SR, Alicuben ET, Oh DS, Lipham JC, Hagen JA, et al. Intraopera- tive Assessment of Perfusion of the Gastric Graft and Correlation With Anastomotic Leaks After Esophagectomy. Ann Surg. 2015;262:74-8.

12. Kumagai Y, Hatano S, Sobajima J, Ishiguro T, Fukuchi M, Ishibashi KI, et al. Indocyanine green fluorescence angiography of the reconstructed gastric tube during esophagectomy: efficacy of the 90-second rule. Dis Esophagus. 2018;31(12). doi: 10.1093/dote/doy052.

13. Di Furia M, Romano L, Salvatorelli A, Brandolin D, Lomanto D, Cianca G, et al. Indocyanine Green Fluorescent Angiography During Laparoscopic Sleeve Gastrectomy: Preliminary Results. Obes Surg. 2019;29:3786-90.

14. Jafari MD, Wexner SD, Martz JE, McLemore EC, Margolin DA, Sherwinter DA, et al. Perfusion assessment in laparoscopic left-sided/anterior resection (PILLAR II): a multi-institutional study. J Am Coll Surg. 2015;220:82-92.

15. Degett TH, Andersen HS, Gögenur I. Indo- cyanine green fluorescence angiography for intraoperative assessment of gastrointestinal anastomotic perfusion: a systematic review of clinical trials. Langenbecks Arch Surg. 2016 Sep;401 767-75.

16. Ris F, Liot E, Buchs NC, Kraus R, Ismael G, Belfontali V, et al.; Near-Infrared Anastomotic Perfusion Assessment Network VOIR. Multicentre phase II trial o near-infrared imaging in elective colorectal surgery. Br J Surg. 2018;105:1359-67.

17. Morales-Conde S, Alarcón I, Yang T, et al. Fluorescence angiography with indocyanine green (ICG) to evaluate anastomosis in colorectal surgery: where does it have more value? Surg Endosc. 2020;34:3897-907. doi 10.1007/s00464019-07159-1.
18. Shapera E, Hsiung RW. Assessment of Anastomotic Perfusion in Left-Sided Robotic Assisted Colorectal Resection by Indocyanine Green Fluorescence Angiography. Minim Invasive Surg. 2019;2019:3267217.

19. Hellan M, Spinoglio G, Pigazzi A, Lagares-Garcia JA. The influence of fluorescence imaging on the location of bowel transection during robotic left-sided colorectal surgery. Surg Endosc. 2014;28:1695-702.

20. Frattini F, Lavazza M, Mangano A, Amico F, Rausei S, Rovera F, et al. Indocyanine green-enhanced fluorescence in laparoscopic sleeve gastrectomy. Obes Surg. 2015;25:949-50.

21. Pesce A, Piccolo G, La Greca G, Puleo S. Utility of fluorescent cholangiography during laparoscopic cholecystectomy: A systematic review. World J Gastroenterol. 2015;21:7877-83.

22. Vlek SL, van Dam DA, Rubinstein SM, Lange-de Klerk ESM, Schoonmade LJ, Tuynman JB, et al. Biliary tract visualization using near-infrared imaging with indocyanine green during laparoscopic cholecystectomy: results of a systematic review. Surg Endosc. 2017;31:2731-42.

23. Machado MA, Surjan RC, Ardengh AO, Makdissi F. Robotic Left Hepatectomy and Roux-en-Y Hepaticojejunostomy After Bile Duct Injury. Ann Surg Oncol. 2019;26:2981-4.

24. Verbeek FP, Schaafsma BE, Tummers QR, van der Vorst JR, van der Made WJ, Baeten CIM, et al. Optimization of near-infrared fluorescence cholangiography for open and laparoscopic surgery. Surg Endosc. 2014;28:1076-82.

25. Hemming AW, Scudamore CH, Shackleton CR, Pudek M, Erb SR. Indocyanine green clearance as a predictor of successful hepatic resection in cirrhotic patients. Am J Surg. 1992;163:515-8.

26. Qi C, Zhang H, Chen Y, Su S, Wang XF, Huang XQ, et al. Effectiveness and safety of indocyanine green fluorescence imaging-guided hepatectomy for liver tumors: A systematic review and first meta-analysis. Photodiagnosis Photodyn Ther. 2019;28:346-53.

27. Ishizawa T, Fukushima N, Shibahara J, Koichi Masuda, Sumihito Tamura, Taku Aoki, et al. Real-time identification of liver cancers by using indocyanine green fluorescent imaging. Cancer. 2009;115:2491-504.

28. Herrera-Almario G, Patane M, Sarkaria I, Strong VE. Initial report of near-infrared fluorescence imaging as an intraoperative adjunct for lymph node harvesting during robot-assisted laparoscopic gastrectomy. J Surg Oncol. 2016;113:768-70.

29. Cianchi F, Indennitate G, Paoli B, Ortolani M, Lami G, Manetti N, et al. The Clinical Value of Fluorescent Lymphography with Indocyanine Green During Robotic Surgery for Gastric Cancer: a Matched Cohort Study. J Gastrointest Surg. 2020;24:2197-203.1007/s11605-019-04382-y.

30. Machado MAC, Surjan R, Basseres T, Makdissi F. Robotic resection of the uncinate process of the pancreas. J Robot Surg. 2019;13:699-702.

31. Liberale G, Bohlok A, Bormans A, Bouazza F, Galdon MG, El Nakadi I, et al. Indocyanine green fluorescence imaging for sentinel lymph node detection in colorectal cancer: A systematic review. Eur J Surg Oncol. 2018;44:1301-6.

32. Nishigori N, Koyama F, Nakagawa T, Nakamura S, Ueda TU, Inoue T, et al. Visualization of Lymph/Blood Flow in Laparoscopic Colorectal Cancer Surgery by ICG Fluorescence Imaging (Lap-IGFI). Ann Surg Oncol. 2016;23 (Suppl 2):S266-S274.

33. Filippello A, Porcheron J, Klein JP, Cottier M, Barabino G. Affinity of Indocyanine Green in the Detection of Colorectal Peritoneal Carcinomatosis. Surg Innov. 2017;24:103-8.

34. Egloff-Juras C, Bezdetnaya L, Dolivet G, Lassalle HP. NIR fluorescence-guided tumor surgery: new strategies for the use of indocyanine green. Int J Nanomedicine. $2019 ; 14: 7823-38$ 